\title{
Comorbidity of 9/11-Related PTSD and Depression in the World Trade Center Health Registry 10-11 Years Postdisaster
}

\author{
Kimberly Caramanica, ${ }^{1}$ Robert M. Brackbill, ${ }^{1}$ Tim Liao, ${ }^{1}$ and Steven D. Stellman ${ }^{1,2}$ \\ ${ }^{1}$ New York City Department of Health and Mental Hygiene, Long Island City, New York, USA \\ ${ }^{2}$ Department of Epidemiology, Mailman School of Public Health, Columbia University, New York, USA
}

\begin{abstract}
Many studies report elevated prevalence of posttraumatic stress disorder (PTSD) and depression among persons exposed to the September 11, 2001 (9/11) disaster compared to those unexposed; few have evaluated long-term PTSD with comorbid depression. We examined prevalence and risk factors for probable PTSD, probable depression, and both conditions 10-11 years post-9/11 among 29,486 World Trade Center Health Registry enrollees who completed surveys at Wave 1 (2003-2004), Wave 2 (2006-2007), and Wave 3 (2011-2012). Enrollees reporting physician diagnosed pre-9/11 PTSD or depression were excluded. PTSD was defined as scoring $\geq 44$ on the PTSD Checklist and depression as scoring $\geq 10$ on the 8-item Patient Health Questionnaire. We examined 4 groups: comorbid PTSD and depression, PTSD only, depression only, and neither. Among enrollees, 15.2\% reported symptoms indicative of PTSD at Wave 3, 14.9\% of depression, and $10.1 \%$ of both. Comorbid PTSD and depression was associated with high 9/11 exposures, low social integration, health-related unemployment, and experiencing $\geq 1$ traumatic life event post-9/11. Comorbid persons experienced poorer outcomes on all PTSD-related impairment measures, life satisfaction, overall health, and unmet mental health care need compared to those with only a single condition. These findings highlight the importance of ongoing screening and treatment for both conditions, particularly among those at risk for mental health comorbidity.
\end{abstract}

Elevated rates of posttraumatic stress disorder (PTSD) and depression have been described among New York City (NYC) residents (Adams \& Boscarino, 2011; Galea et al., 2002; Hobfoll, Tracy, \& Galea, 2006) and rescue and recovery workers (Chiu et al., 2011; Stellman et al., 2008; Wisnivesky et al., 2011) exposed to the September 11, 2001 (9/11) disaster. The World Trade Center Health Registry (the Registry) has consistently yielded a prevalence of $10 \%$ or more of 9/11-related PTSD among adult rescue and recovery workers and lower Manhattan residents and area workers/passersby (Brackbill et al., 2009). PTSD is often comorbid with other mental health conditions

This study was supported by Cooperative Agreement U50/OH009739 from the National Institute for Occupational Safety and Health; Cooperative Agreement U50/ATU272750 from the Agency for Toxic Substances and Disease Registry of the Centers for Disease Control and Prevention, which included support from the National Center for Environmental Health (NCEH); and the New York City Department of Health and Mental Hygiene. Its contents are solely the responsibility of the authors and do not necessarily represent the official views of Centers for Disease Control. The authors are grateful for the helpful input and comments from Drs. Howard Alper, Carolyn Greene, Mark Farfel, and Alice Welch.

Correspondence concerning this article should be addressed to Kimberly Caramanica, New York City Department of Health and Mental Hygiene, World Trade Center Health Registry, 42-09 28 ${ }^{\text {th }}$ Street, Long Island City, New York 11101. E-mail: kcaramanica@ health.nyc.gov

Copyright (c) 2014 International Society for Traumatic Stress Studies. View this article online at wileyonlinelibrary.com

DOI: $10.1002 /$ jts. 21972 such as generalized anxiety and depression (Gadermann, Alonso, Vilagut, Zaslavsky, \& Kessler, 2012). In traumatized populations, comorbid PTSD and depression is associated with increased functional impairment, reduced quality of life, impaired life satisfaction, greater symptom severity, and disability relative to either condition alone (Ikin, Creamer, Sim, \& McKenzie, 2010).

Few studies conducted among 9/11-exposed individuals provide estimates of the comorbidity of PTSD and depression or examine downstream issues related to quality of life and unmet mental health care need. A large telephone survey of Englishand Spanish-speaking adults residing in Manhattan conducted 1-2 months post-9/11 found that $3.7 \%$ of respondents reported symptoms that met the criteria for both PTSD and depression (Galea et al., 2002). In a study of retired World Trade Center (WTC) exposed firefighters, more than $70 \%$ of PTSD and depression cases were co-occurring 4-6 years post-9/11 (Chiu et al., 2011). Up to 5 years post-9/11, $4.7 \%$ of WTC rescue and recovery workers other than firefighters reported probable PTSD plus either panic disorder or depression, and $1.7 \%$ reported probable PTSD plus both panic disorder and depression (Stellman et al., 2008); in the same longitudinal study, 5.1\% of $9 / 11$ rescue and recovery workers reported symptoms consistent with PTSD and depression 9 years postevent (Wisnivesky et al., 2011).

Risk factors for 9/11-related PTSD and depression were reported in several studies. Early arrival at the WTC site was a risk 
factor for PTSD (Chiu et al., 2011), whereas problem alcohol use, perievent panic attack, and predisaster psychological problems were associated with depression (Adams \& Boscarino, 2011; Chiu et al., 2011); disability retirement and total loss of resources were risk factors for both PTSD and depression among NYC residents (Hobfoll et al., 2006) and firefighters (Chiu et al., 2011), respectively.

We are aware of only one study of rescue and recovery workers that has documented long-term depression up to 9 years post-9/11 (Wisnivesky et al., 2011). Long-term depression prevalence among others exposed to the 9/11 disaster remains unknown. The purpose of the current study was first to determine the long-term (10-11 years post-9/11) prevalence of PTSD, depression, and comorbid PTSD and depression among adult Registry enrollees, a diverse group of individuals directly exposed to the events of $9 / 11$. Second, we sought to identify risk factors associated with having PTSD only, depression only, or both conditions. Third, we wanted to examine quality of life and unmet mental health care need among those with PTSD, depression, and both conditions. Last, we aimed to explore the relationship between poor mental health and PTSD-related impairment among enrollees with PTSD and comorbid PTSD and depression.

\section{Method}

\section{Participants and Procedure}

The study sample was drawn from the Registry, a cohort of 71,434 persons exposed to the WTC attacks on 9/11. Details of the cohort and recruitment methods have been published elsewhere (Brackbill et al., 2009; Murphy et al., 2007). The present study includes rescue and recovery workers and lower Manhattan area workers, passersby, and residents. There were two modes of Registry enrollment; list-identified enrollees (29.7\%) were actively recruited from contact lists provided by governmental agencies, organizations, and employers, whereas selfidentified enrollees $(70.3 \%)$ contacted the Registry via phone or preregistered on a website in response to intensive outreach efforts. The Registry protocol was approved by the institutional review boards of the Centers for Disease Control and Prevention and the NYC Department of Health and Mental Hygiene.

\section{Study Sample}

A total of 36,104 adult enrollees completed Wave 1 (20032004), Wave 2 (2006-2007), and Wave 3 (2011-2012). Wave 1 data collection consisted of both computer-assisted telephone interviewing (CATI; 95\%) and computer-assisted personal interviewing (CAPI; 5\%). Waves 2 and 3 employed web, paper, and CATI surveys, with response rates of $68 \%$ and $63 \%$, respectively. Enrollees with a self-reported professional diagnosis of PTSD $(n=490)$ or depression $(n=2,685)$ prior to $9 / 11$, PTSD $(n=229)$ or depression $(n=379)$ with a missing date of diagnosis, or missing information on history of PTSD $(n=1,004)$ or depression $(n=899)$ diagnosis at Wave 2 were excluded. Enrollees missing PCL-17 item(s) $(n=1,662)$ or PHQ-8 item(s) $(n=1,379)$ at Wave 3 were also excluded, resulting in a final sample of 29,486 .

Enrollees had the following characteristics: male (64.1\%), aged 45-64 years $(61.2 \%)$, non-Hispanic White (72.6\%), married or living with a partner $(71.5 \%)$, a college or postgraduate education (54.3\%), employed (72.7\%), self-identified enrollment source $(75.4 \%)$, and household income $>\$ 75,000$ $(63.0 \%)$. Nearly half were rescue and recovery workers (48.8\%; Table 1).

\section{Measures}

Probable PTSD was assessed in Registry Wave 1, 2, and 3 surveys using the PTSD Checklist-Civilian Version (PCL-17), a self-reported, 17-item scale that corresponds to the three PTSD symptom clusters (reexperiencing, avoidance, hyperarousal) as outlined in the Diagnostic and Statistical Manual of Mental Disorders (4th ed., DSM-IV; American Psychiatric Association, 1994; Blanchard, Jones-Alexander, Buckley, \& Forneris, 1996; Ruggiero, Del Ben, Scotti, \& Rabalais, 2003); the psychometric properties of the PCL-17 have been reported elsewhere (Blanchard et al., 1996; Ruggiero et al., 2003). Respondents rated symptom severity on a 5 -point scale from $1=$ not at all to $5=$ extremely; selected symptoms were queried as specific to $9 / 11$ and all were current (within the last 30 days). As in previous Registry studies (Brackbill et al., 2009), enrollees with a PCL-17 score of $\geq 44$ at Wave 3 were considered to have probable PTSD (hereafter referred to as PTSD).

An 8-item Patient Health Questionnaire (PHQ-8), introduced in Wave 3, assessed depression. Enrollees rated symptom severity in the last 2 weeks on a 4-point scale from $0=$ not at all to 3 = nearly every day. The PHQ-8 consists of eight of the nine criteria on which a diagnosis of DSM-IV depression is based (Kroenke, Spitzer, \& Williams, 2001). A cutoff score of 10 has been shown to have .88 sensitivity and .88 specificity for depression and typically represents clinically significant depression (Kroenke et al., 2001). Scores for each item were summed (range 0-24) and respondents with a PHQ-8 score of $\geq 10$ at Wave 3 were considered to have depression.

A 4-level categorical variable was created based on enrollee responses to the PCL-17 and PHQ-8 at Wave 3: comorbid PTSD and depression (PTSD+, depression+), PTSD only (PTSD+, depression-), depression only (PTSD-, depression + ), and no PTSD and no depression (PTSD-, depression-).

Exposure to 9/11 was defined with a summary measure used previously (Brackbill, Stellman, Perlman, Walker, \& Farfel, 2013), and is modeled after work by Adams, Boscarino, and Galea (2006). As adapted by Brackbill et al. (2013), 9/11 exposure was categorized as none/low (0-1 exposures), medium (2-3), high (4-5), and very high $(\geq 6)$. This scale covers several dimensions of 9/11-related exposure, including dust cloud exposure, injury, witnessing horror, bereavement, home evacuation, and others. Each item has been shown to be associated 
Table 1

Sociodemographic Characteristics, 9/11 Exposures, and Experiences of Adult Registry Enrollees at Wave 3

\begin{tabular}{|c|c|c|c|c|c|c|}
\hline \multirow[b]{3}{*}{ Variable } & \multirow{2}{*}{\multicolumn{2}{|c|}{$\begin{array}{l}\text { Overall sample } \\
(n=29,486)\end{array}$}} & \multicolumn{2}{|c|}{ PTSD+ } & \multicolumn{2}{|c|}{ PTSD- } \\
\hline & & & \multirow{2}{*}{$\begin{array}{c}\text { Depression+ } \\
(n=2,985) \\
\%\end{array}$} & \multirow{2}{*}{$\begin{array}{c}\text { Depression- } \\
(n=1,504) \\
\%\end{array}$} & \multirow{2}{*}{$\begin{array}{c}\text { Depression+ } \\
(n=1,407) \\
\%\end{array}$} & \multirow{2}{*}{$\begin{array}{c}\text { Depression- } \\
(n=23,590) \\
\%\end{array}$} \\
\hline & $n$ & $\%$ & & & & \\
\hline Total & 29,486 & 100.0 & 10.1 & 5.1 & 4.8 & 80.0 \\
\hline \multicolumn{7}{|l|}{ Gender } \\
\hline Male & 18,899 & 64.1 & 10.1 & 4.7 & 4.7 & 80.6 \\
\hline Female & 10,587 & 35.9 & 10.2 & 5.9 & 4.9 & 79.0 \\
\hline \multicolumn{7}{|l|}{ Age group (years) ${ }^{\mathrm{a}}$} \\
\hline $18-29$ & 450 & 1.5 & 7.6 & 3.6 & 5.1 & 83.8 \\
\hline $30-44$ & 7,155 & 24.3 & 9.3 & 5.1 & 4.9 & 80.7 \\
\hline $45-64$ & 18,035 & 61.2 & 11.5 & 5.5 & 4.9 & 78.1 \\
\hline $65+$ & 3,846 & 13.0 & 5.4 & 3.7 & 3.9 & 87.0 \\
\hline \multicolumn{7}{|l|}{ Race/Ethnicity } \\
\hline Non-Hispanic White & 21,407 & 72.6 & 8.9 & 4.6 & 4.6 & 82.0 \\
\hline Non-Hispanic Black & 2,724 & 9.2 & 11.6 & 6.7 & 4.6 & 77.1 \\
\hline Hispanic or Latino & 3,031 & 10.3 & 17.5 & 7.1 & 5.2 & 70.2 \\
\hline Asian & 1,447 & 4.9 & 8.6 & 4.8 & 5.9 & 80.7 \\
\hline Multiracial/other & 877 & 3.0 & 13.3 & 6.4 & 7.3 & 73.0 \\
\hline \multicolumn{7}{|l|}{ Household income ${ }^{\mathrm{a}}$} \\
\hline$\leq \$ 25,000$ & 2,123 & 7.6 & 25.3 & 6.8 & 7.6 & 60.3 \\
\hline$\$ 25,001-\$ 50,000$ & 3,541 & 12.6 & 15.4 & 6.7 & 6.1 & 71.8 \\
\hline$\$ 50,001-\$ 75,000$ & 4,719 & 16.8 & 11.8 & 6.0 & 5.5 & 76.7 \\
\hline$\$ 75,001-\$ 150,000$ & 11,131 & 39.7 & 8.3 & 4.9 & 4.6 & 82.2 \\
\hline$\$ 150,000+$ & 6,519 & 23.3 & 4.8 & 3.8 & 3.1 & 88.3 \\
\hline \multicolumn{7}{|l|}{ Marital status ${ }^{\mathrm{a}}$} \\
\hline Married/living with partner & 20,981 & 71.5 & 8.8 & 4.8 & 4.2 & 82.1 \\
\hline Divorced/separated & 3,512 & 12.0 & 16.5 & 6.3 & 6.5 & 70.7 \\
\hline Widowed & 780 & 2.7 & 12.3 & 6.4 & 5.4 & 75.9 \\
\hline Never married & 4,066 & 13.9 & 10.8 & 5.3 & 6.1 & 77.9 \\
\hline \multicolumn{7}{|l|}{ Education $^{\mathrm{b}}$} \\
\hline Less than high school & 732 & 2.5 & 18.2 & 7.7 & 7.3 & 66.9 \\
\hline High school graduate/GED & 5,255 & 17.9 & 13.8 & 5.9 & 5.3 & 75.1 \\
\hline Some college & 7,433 & 25.3 & 12.4 & 5.8 & 5.1 & 76.7 \\
\hline College/postgraduate & 15,923 & 54.3 & 7.4 & 4.4 & 4.4 & 83.8 \\
\hline \multicolumn{7}{|l|}{ Employment $^{\mathrm{a}}$} \\
\hline Employed & 21,357 & 72.7 & 7.9 & 4.9 & 4.5 & 82.6 \\
\hline $\begin{array}{l}\text { Unemployed for reasons other } \\
\text { than health }\end{array}$ & 1,307 & 4.5 & 17.7 & 5.7 & 8.0 & 68.6 \\
\hline $\begin{array}{l}\text { Unemployed for health } \\
\text { reasons }\end{array}$ & 961 & 3.3 & 50.4 & 8.6 & 8.4 & 32.6 \\
\hline Homemaker or student & 891 & 3.0 & 9.7 & 4.2 & 5.7 & 80.5 \\
\hline Retired & 4,855 & 16.5 & 9.9 & 5.1 & 4.0 & 81.0 \\
\hline \multicolumn{7}{|l|}{ Job loss ${ }^{c}$} \\
\hline Job loss & 1,497 & 5.1 & 25.3 & 5.9 & 8.6 & 60.2 \\
\hline No job loss & 27,746 & 94.9 & 9.3 & 5.1 & 4.6 & 81.1 \\
\hline \multicolumn{7}{|l|}{ Enrollment } \\
\hline List-identified & 7,244 & 24.6 & 7.4 & 3.5 & 4.5 & 84.6 \\
\hline Self-identified & 22,242 & 75.4 & 11.0 & 5.6 & 4.9 & 78.5 \\
\hline
\end{tabular}


Table 1

Continued

\begin{tabular}{|c|c|c|c|c|c|c|}
\hline \multirow[b]{3}{*}{ Variable } & \multirow{2}{*}{\multicolumn{2}{|c|}{$\begin{array}{l}\text { Overall sample } \\
(n=29,486)\end{array}$}} & \multicolumn{2}{|c|}{ PTSD+ } & \multicolumn{2}{|c|}{ PTSD- } \\
\hline & & & \multirow{2}{*}{$\begin{array}{c}\text { Depression+ } \\
(n=2,985) \\
\%\end{array}$} & \multirow{2}{*}{$\begin{array}{c}\text { Depression- } \\
(n=1,504) \\
\%\end{array}$} & \multirow{2}{*}{$\begin{array}{c}\text { Depression+ } \\
(n=1,407) \\
\%\end{array}$} & \multirow{2}{*}{$\begin{array}{c}\text { Depression- } \\
(n=23,590) \\
\%\end{array}$} \\
\hline & $n$ & $\%$ & & & & \\
\hline \multicolumn{7}{|l|}{ Eligibility group } \\
\hline Rescue and recovery worker & 14,391 & 48.8 & 10.9 & 5.1 & 4.7 & 79.4 \\
\hline $\begin{array}{l}\text { Lower Manhattan area } \\
\text { worker/passerby }\end{array}$ & 11,505 & 39.0 & 9.9 & 5.6 & 4.8 & 79.7 \\
\hline Lower Manhattan resident & 3,590 & 12.2 & 7.8 & 3.5 & 5.2 & 83.5 \\
\hline \multicolumn{7}{|l|}{ 9/11 exposure scale } \\
\hline None/low (0-1 exposures) & 7,410 & 25.1 & 3.8 & 1.6 & 4.4 & 90.2 \\
\hline Medium (2-3 exposures) & 12,426 & 42.1 & 8.0 & 4.4 & 4.8 & 82.9 \\
\hline High (4-5 exposures) & 6,916 & 23.5 & 14.7 & 7.6 & 5.4 & 72.4 \\
\hline Very high (6-11 exposures) & 2,734 & 9.3 & 25.3 & 11.7 & 4.4 & 58.6 \\
\hline \multicolumn{7}{|l|}{ Social integration sources ${ }^{\mathrm{d}}$} \\
\hline None & 356 & 1.2 & 38.8 & 9.3 & 7.0 & 44.9 \\
\hline 1 & 1,836 & 6.2 & 24.0 & 7.8 & 7.7 & 60.4 \\
\hline 2 & 13,283 & 45.1 & 10.5 & 5.4 & 5.3 & 78.8 \\
\hline 3 & 8,567 & 29.1 & 8.4 & 4.6 & 4.3 & 82.8 \\
\hline 4 & 5,413 & 18.4 & 5.4 & 3.9 & 3.2 & 87.5 \\
\hline \multicolumn{7}{|l|}{ Traumatic life events post-9/11 } \\
\hline 0 & 19,683 & 67.1 & 7.7 & 4.4 & 3.9 & 84.0 \\
\hline 1 & 5,397 & 18.4 & 11.3 & 5.7 & 6.2 & 76.9 \\
\hline$>1$ & 4,261 & 14.5 & 19.7 & 7.6 & 6.8 & 66.0 \\
\hline \multicolumn{7}{|c|}{ Self-reported PTSD and depression ${ }^{\mathrm{d}}$} \\
\hline PTSD+ Depression+ & 2,536 & 8.6 & 43.4 & 12.0 & 7.4 & 37.2 \\
\hline PTSD+ Depression- & 1,477 & 5.0 & 13.7 & 13.7 & 5.1 & 67.6 \\
\hline PTSD- Depression+ & 2,119 & 7.2 & 20.9 & 7.1 & 12.3 & 59.7 \\
\hline PTSD- Depression- & 23,354 & 79.2 & 5.3 & 3.6 & 3.8 & 87.3 \\
\hline \multicolumn{7}{|l|}{ PTSD-impairment difficulties ${ }^{\mathrm{a}}$} \\
\hline Not at all & 15,900 & 61.8 & 0.8 & 1.9 & 1.9 & 95.4 \\
\hline Somewhat & 8,278 & 32.2 & 19.6 & 13.2 & 11.4 & 55.8 \\
\hline Very much & 1,114 & 4.3 & 74.5 & 7.6 & 11.0 & 6.9 \\
\hline Extremely difficult & 454 & 1.8 & 85.2 & 5.1 & 5.3 & 4.4 \\
\hline
\end{tabular}

Note. 9/11 = September 11, 2001; PTSD = posttraumatic stress disorder; GED = general equivalency diploma. All percentages expressed as row percents. Percent missing not shown. Effective range of $n$ : PTSD+ Depression $+n=2,876-2,985$; PTSD + Depression- $n=1,458-1,504$; PTSD- Depression $+n=1,355-1,407$; PTSD- Depression- $n=19,887-23,590$. For all variables $p<.0001$.

${ }^{\mathrm{a}}$ At Wave 3. ${ }^{\mathrm{b}}$ At Wave 1. ${ }^{\mathrm{c}}$ Enrollee who reported being employed at Wave 2 and reported being unemployed at Wave 3 . ${ }^{\mathrm{d}}$ At Wave 2.

with physical and/or mental health outcomes in previous Registry studies.

Low levels of social integration were associated with PTSD in a previous Registry study (Brackbill et al., 2013). A social integration scale with a range of 0 to 4 was created by summing the number of positive responses to each of the following indicators from Wave 2: having one or more close friends; seeing, talking to, or e-mailing with friends or relatives at least 2-3 times per month; attending religious services at least 2-3 times per month; and being very or fairly active in the affairs of at least one volunteer group or organization (Brackbill et al., 2013).

We adjusted for post-9/11 traumatic life events, as PTSD can result from trauma other than the WTC disaster. Traumatic life event score at Wave 3 was based on endorsement of up to eight events or situations post-9/11, including being exposed to a natural or human-made disaster, a serious accident, attacked with or without a weapon, unwanted sexual contact, or 
life-threatening illness. Items in which the respondent endorsed a post-9/11 trauma received a score of 1 . All endorsed items were summed and categorized as none, 1 , or $>1$ traumatic life event post-9/11.

At Wave 2, enrollees were asked to report if they had ever been diagnosed with PTSD or depression by a doctor or other health professional, the year they were first diagnosed, and if in 2001, whether they were diagnosed pre-9/11. A 4-level categorical variable was created from their responses: comorbid diagnosed PTSD and depression (PTSD+, depression+), PTSD only (PTSD+, depression-), depression only (PTSD-, depression+), and no PTSD and no depression (PTSD-, depression-).

Enrollees who endorsed at least one PTSD symptom item on the PCL-17 at Wave 3 were asked to report how difficult those problems made it for them to do their work, take care of things at home, or get along with other people. PTSD symptom duration was dichotomized into experiencing or not experiencing any problems associated with a symptom continuously for one month in the past 12 months (Blanchard et al., 1996).

Life satisfaction at Wave 3 was measured on a 4-point scale from very satisfied to very dissatisfied. General health status was based on a self-rating of health from excellent to poor (Zahran et al., 2005).

Enrollees reported the number of days in the last 30 days in which their physical or mental health was "not good" at Wave 3. Physical and mental health responses were categorized as $\geq$ 14 days or $<14$ days of poor health (Zahran et al., 2005).

Unmet mental health care need at Wave 3 was defined as a self-report of needing but not receiving mental health care or counseling in the preceding 12 months (Brackbill et al., 2013).

\section{Data Analysis}

Pearson $\chi^{2}$ tests were used to test for significant associations between comorbid PTSD and depression and selected sociodemographic characteristics, 9/11 exposures and experiences, quality of life, and unmet mental health care need. Multinomial logistic regression was performed and adjusted odds ratios (AORs) and $95 \%$ confidence intervals (CIs) were calculated to estimate the strength of the association between selected covariates and PTSD, depression, and comorbid PTSD and depression; no PTSD and no depression was used as the reference. All analyses were conducted using SAS Version 9.2 (SAS, 2008).

\section{Results}

Among adult enrollees $15.2 \%$ reported symptoms indicative of PTSD 10-11 years post-9/11 and 14.9\% met criteria for depression; $10.1 \%$ experienced both. Prevalence of comorbid PTSD and depression varied by age, and was lowest among individuals $\geq 65$ years (5.4\%) and highest among those 45-64 years (11.5\%; Table 1). The proportion of comorbid PTSD and depression was highest among Hispanics (17.5\%) and those with income of $\leq \$ 25,000$ (25.3\%), less than a high school education (18.2\%), who were divorced or separated (16.5\%), unemployed for reasons other than health $(17.7 \%)$ or unemployed for health reasons (50.4\%), who had experienced job loss between Waves 2 and 3 (25.3\%), and who reported a professional diagnosis of both conditions by Wave $2(43.4 \%)$ when compared to their counterparts $(p$ values $<.05)$. Rescue and recovery workers $(10.9 \%)$ had the highest prevalence of comorbid PTSD and depression whereas residents $(7.8 \%)$ had the lowest.

The prevalence of comorbid PTSD and depression increased with increasing number of $9 / 11$ exposures, with the highest prevalence among those with very high (25.3\%) 9/11 exposure. A gradient was also observed for social integration, as those with none $(38.8 \%)$ or one $(24.0 \%)$ source of social integration reported the highest prevalence of comorbid PTSD and depression. Post-9/11 trauma history was also strongly associated with the prevalence of comorbid PTSD and depression, and was elevated among enrollees who experienced 1 (11.3\%) or $>1(19.7 \%)$ traumatic life event after $9 / 11$.

The AORs of comorbid PTSD and depression were greater among rescue and recovery workers, $A O R=1.36,95 \% \mathrm{CI}$ $[1.14,1.62]$ and area workers/passersby, $A O R=1.33,95 \% \mathrm{CI}$ $[1.12,1.57]$ compared to residents (Table 2). A dose-response relationship was observed for the association between 9/11 exposures and comorbidity, with the greatest likelihood of comorbidity among enrollees with high or very high $9 / 11$ exposures compared to those with none/low exposures, $A O R=3.19,95 \%$ CI $[2.73,3.74] ; A O R=4.15,95 \%$ CI $[3.46,4.97]$, respectively. Lack of social integration was significantly associated with increased odds of comorbidity, as individuals with none or one source of social integration were more likely to experience comorbid PTSD and depression, $A O R=7.53,95 \% \mathrm{CI}$ $[5.43,10.43] ; A O R=4.31,95 \%$ CI [3.55, 5.23], respectively, compared to those with four sources. The likelihood of having comorbid PTSD and depression was elevated among enrollees who were unemployed for reasons other than health, $A O R=$ $1.79,95 \%$ CI $[1.49,2.15]$, or who were unemployed for health reasons, $A O R=4.57,95 \% \mathrm{CI}[3.76,5.56]$ compared to those employed sometime during 2011-2012. The odds of comorbidity were also higher for individuals who had experienced one or more traumatic life events since $9 / 11, A O R=1.42,95 \%$ CI $[1.26,1.60] ; A O R=2.37,95 \%$ CI $[2.11,2.66]$, respectively. Lastly, significant associations were observed between professionally diagnosed PTSD and depression at Wave 2 and comorbid PTSD and depression at Wave 3.

PTSD only and depression only groups showed similar patterns for social integration and post-9/11 trauma exposure, with elevated odds observed among those with no sources of social integration, $A O R=3.64,95 \%$ CI $[2.35,5.63] ; A O R=$ $3.24,95 \%$ CI $[2.02,5.19]$, respectively, and $>1$ traumatic life event after 9/11, AOR $=1.76,95 \%$ CI $[1.52,2.05] ; A O R=$ $2.07,95 \%$ CI [1.77, 2.41], respectively. Employment status at Wave 3 was more strongly associated with depression status 
Table 2

Adjusted Odds Ratios (AORs) and 95\% Confidence Intervals (CIs) for Association Between PTSD, Depression, or Both, and Selected 9/11 Exposures and Experiences at Wave 3

\begin{tabular}{|c|c|c|c|c|c|c|}
\hline \multirow[b]{4}{*}{ Variable } & \multicolumn{4}{|c|}{ PTSD+ } & \multirow{3}{*}{\multicolumn{2}{|c|}{$\frac{\text { PTSD- }}{{\text { Depression }{ }^{\mathrm{a}}}^{\text {Pep }}}$}} \\
\hline & \multirow{2}{*}{\multicolumn{2}{|c|}{$\frac{\text { Depression }^{\mathrm{a}}}{(n=2,985)}$}} & \multirow{2}{*}{\multicolumn{2}{|c|}{$\frac{\text { Depression- }^{\mathrm{a}}}{(n=1,504)}$}} & & \\
\hline & & & & & & \\
\hline & $A O R$ & $95 \% \mathrm{CI}$ & $A O R$ & $95 \% \mathrm{CI}$ & $A O R$ & $95 \% \mathrm{CI}$ \\
\hline \multicolumn{7}{|l|}{ Eligibility group } \\
\hline Rescue and recovery worker & 1.36 & {$[1.14,1.62]$} & 1.61 & {$[1.29,2.02]$} & 1.01 & {$[0.83,1.23]$} \\
\hline Lower Manhattan area worker/passerby & 1.33 & {$[1.12,1.57]$} & 1.67 & {$[1.35,2.07]$} & 1.10 & {$[0.91,1.33]$} \\
\hline \multicolumn{7}{|l|}{ 9/11 exposures } \\
\hline $2-3$ & 1.83 & {$[1.57,2.13]$} & 2.63 & {$[2.13,3.25]$} & 1.09 & {$[0.94,1.27]$} \\
\hline $4-5$ & 3.19 & {$[2.73,3.74]$} & 4.58 & {$[3.69,5.69]$} & 1.30 & {$[1.10,1.54]$} \\
\hline $6-11$ & 4.15 & {$[3.46,4.97]$} & 6.80 & {$[5.36,8.64]$} & 1.04 & {$[0.82,1.32]$} \\
\hline \multicolumn{7}{|l|}{ Social integration sources ${ }^{\mathrm{a}}$} \\
\hline None & 7.53 & {$[5.43,10.43]$} & 3.64 & {$[2.35,5.63]$} & 3.24 & {$[2.02,5.19]$} \\
\hline 1 & 4.31 & {$[3.55,5.23]$} & 2.44 & {$[1.92,3.10]$} & 2.77 & {$[2.17,3.55]$} \\
\hline 2 & 1.84 & {$[1.58,2.15]$} & 1.45 & {$[1.22,1.72]$} & 1.63 & {$[1.36,1.96]$} \\
\hline 3 & 1.46 & {$[1.24,1.72]$} & 1.13 & {$[0.94,1.36]$} & 1.32 & {$[1.08,1.60]$} \\
\hline \multicolumn{7}{|l|}{ Employment $^{\mathrm{b}}$} \\
\hline Unemployed for reasons other than health & 1.79 & {$[1.49,2.15]$} & 1.05 & {$[0.81,1.37]$} & 1.57 & {$[1.25,2.00]$} \\
\hline Unemployed for health reasons & 4.57 & {$[3.76,5.56]$} & 2.00 & {$[1.50,2.65]$} & 2.45 & {$[1.85,3.25]$} \\
\hline Homemaker or student & 1.05 & {$[0.79,1.40]$} & 0.85 & {$[0.59,1.22]$} & 1.29 & {$[0.94,1.78]$} \\
\hline Retired & 1.11 & {$[0.96,1.28]$} & 0.99 & {$[0.83,1.18]$} & 0.85 & {$[0.70,1.03]$} \\
\hline \multicolumn{7}{|l|}{ Traumatic life events post-9/11 } \\
\hline 1 & 1.42 & {$[1.26,1.60]$} & 1.28 & {$[1.11,1.47]$} & 1.58 & {$[1.37,1.81]$} \\
\hline$<1$ & 2.37 & {$[2.11,2.66]$} & 1.76 & {$[1.52,2.05]$} & 2.07 & {$[1.77,2.41]$} \\
\hline \multicolumn{7}{|l|}{ Self-reported PTSD and depression ${ }^{a}$} \\
\hline PTSD+ Depression+ & 9.82 & {$[8.69,11.10]$} & 4.56 & {$[3.88,5.36]$} & 3.51 & {$[2.92,4.23]$} \\
\hline PTSD+ Depression- & 2.74 & {$[2.29,3.28]$} & 3.86 & {$[3.22,4.61]$} & 1.74 & {$[1.35,2.24]$} \\
\hline PTSD- Depression+ & 4.50 & {$[3.92,5.17]$} & 2.42 & {$[2.00,2.94]$} & 4.10 & {$[3.51,4.81]$} \\
\hline
\end{tabular}

Note. 9/11 = September 11, 2001; PTSD = posttraumatic stress disorder. Adjusted for gender, age group, race/ethnicity, income, marital status, education, enrollment, and interview mode at Wave 3. Reference for each variable is as follows: eligibility group $=$ Lower Manhattan resident; $9 / 11$ exposure scale $=$ none/low $(0-1$ exposures); social integration $=4$ sources; employment $=$ employed; traumatic life events post-9/11 $=0$; self-reported PTSD and depression diagnosis $=$ PTSD - depression - .

${ }^{\mathrm{a}}$ At Wave 2. ${ }^{\mathrm{b}}$ At Wave 3.

than PTSD status, as those who were unemployed due to reasons other than health or unemployed for health reasons had a greater likelihood of depression only, $A O R=1.57,95 \%$ CI $[1.25,2.00] ; A O R=2.45,95 \%$ CI $[1.85,3.25]$, respectively, when compared to individuals with no PTSD or depression. In contrast, 9/11 exposure and eligibility group was associated more strongly with PTSD than depression; significantly higher odds of PTSD were observed across all levels of 9/11 exposure when compared to those with depression only.

On virtually all measures of PTSD-related impairment, quality of life, and perceived unmet mental health care need, poorer outcomes were observed among those with comorbid PTSD and depression when compared to those with only one condition
(Table 3). For example, among those with comorbid PTSD and depression, enrollees frequently reported PTSD symptom duration of $>1$ month $(82.0 \%)$, low levels of life satisfaction, fair $(44.1 \%)$ or poor $(23.6 \%)$ overall health, $\geq 14$ poor physical $(49.1 \%)$ or mental $(74.0 \%)$ health days in the last 30 days, and perceived unmet mental health care need $(40.2 \%)$ in the year prior.

For those with PTSD only and comorbid PTSD and depression, the mean number of poor mental health days increased with increasing difficulty functioning (Figure 1). At every PTSD-related impairment level, however, the mean number of poor mental health days was significantly higher in the comorbid group than in the PTSD only group. 
Table 3

Quality of Life and Unmet Mental Health Care Need Among Adult Registry Enrollees With PTSD, Depression, or Both at Wave 3

\begin{tabular}{|c|c|c|c|c|c|c|}
\hline \multirow[b]{4}{*}{ Variable } & \multicolumn{4}{|c|}{ PTSD+ } & \multirow{2}{*}{\multicolumn{2}{|c|}{$\frac{\text { PTSD- }}{\text { Depression+ }}$}} \\
\hline & \multirow{2}{*}{\multicolumn{2}{|c|}{$\begin{array}{c}\text { Depression+ } \\
(n=2,985)\end{array}$}} & \multirow{2}{*}{\multicolumn{2}{|c|}{$\begin{array}{c}\text { Depression- } \\
(n=1,504)\end{array}$}} & & \\
\hline & & & & & \multicolumn{2}{|c|}{$(n=1,407)$} \\
\hline & $n$ & $\%$ & $n$ & $\%$ & $n$ & $\%$ \\
\hline \multicolumn{7}{|c|}{ PTSD-impairment difficulties } \\
\hline Not at all & 129 & 4.3 & 295 & 19.7 & 304 & 21.9 \\
\hline Somewhat & 1,625 & 54.7 & 1,094 & 73.1 & 941 & 67.7 \\
\hline Very much & 830 & 27.9 & 85 & 5.7 & 122 & 8.8 \\
\hline Extremely difficult & 387 & 13.0 & 23 & 1.5 & 24 & 1.7 \\
\hline \multicolumn{7}{|c|}{ PTSD symptom duration (months) } \\
\hline$>1$ & 2,429 & 82.0 & 843 & 56.4 & 822 & 59.1 \\
\hline$\leq 1$ & 535 & 18.1 & 652 & 43.6 & 568 & 40.9 \\
\hline \multicolumn{7}{|l|}{ Life satisfaction } \\
\hline Very satisfied & 104 & 3.5 & 167 & 11.2 & 66 & 4.7 \\
\hline Satisfied & 1,137 & 38.6 & 1,010 & 67.6 & 747 & 53.4 \\
\hline Dissatisfied & 1,266 & 43.0 & 295 & 19.7 & 502 & 35.9 \\
\hline Very dissatisfied & 437 & 14.8 & 23 & 1.5 & 84 & 6.0 \\
\hline \multicolumn{7}{|l|}{ General health } \\
\hline Excellent & 20 & 0.7 & 37 & 2.5 & 20 & 1.4 \\
\hline Very good & 147 & 5.0 & 222 & 14.8 & 164 & 11.7 \\
\hline Good & 793 & 26.8 & 619 & 41.4 & 549 & 39.2 \\
\hline Fair & 1,306 & 44.1 & 538 & 35.9 & 512 & 36.6 \\
\hline Poor & 698 & 23.6 & 81 & 5.4 & 155 & 11.1 \\
\hline \multicolumn{7}{|c|}{ Poor physical health days } \\
\hline$\geq 14$ & 1,446 & 49.1 & 354 & 23.9 & 474 & 34.0 \\
\hline$<14$ & 1,497 & 50.9 & 1,130 & 76.2 & 921 & 66.0 \\
\hline \multicolumn{7}{|l|}{ Poor mental health days } \\
\hline$\geq 14$ & 2,179 & 74.0 & 523 & 35.2 & 742 & 53.3 \\
\hline$>14$ & 765 & 26.0 & 964 & 64.8 & 650 & 46.7 \\
\hline \multicolumn{7}{|c|}{$\begin{array}{l}\text { Prior } 12 \text { month unmet mental health } \\
\text { care need }\end{array}$} \\
\hline Yes & 1,182 & 40.2 & 324 & 21.8 & 378 & 27.1 \\
\hline No & 1,762 & 59.9 & 1,165 & 78.2 & 1,016 & 72.9 \\
\hline
\end{tabular}

Note. PTSD $=$ posttraumatic stress disorder. All percentages expressed as row percents. Percent missing not shown. Effective range of $n$ : PTSD + Depression $+n=$ 2,943-2,985; PTSD+ Depression- $n=1,484-1,504$; PTSD- Depression $+n=1,390-1,407 . p$ value for PTSD only versus depression only. PTSD symptom duration was not significant; PTSD-related impairment $p=.002$; for all other variables $p<.001$.

\section{Discussion}

More than a decade after $9 / 11,10.1 \%$ of adult Registry enrollees in the present study showed comorbid PTSD and depression. Based on an estimated 409,000 individuals directly exposed to the events of 9/11 using Registry eligibility groups (Murphy et al., 2007), 10-11 years after $9 / 11$ a possible 41,000 individuals in total are projected to suffer from comorbid PTSD and depression, and 16,000 individuals with comorbid PTSD and depression are projected to report unmet mental health care need.

When compared to individuals with PTSD or depression only, those with both conditions were more likely to report a high number of 9/11 exposures and experience poorer outcomes on measures of employment, social integration, quality of life, and perceived unmet mental health care need. In both the comorbid PTSD and depression and PTSD only groups, the mean number of poor mental health days increased with increasing PTSD-related impairment. Although 9/11 exposure and eligibility group was associated with having PTSD only, no significant relationship was observed in the group with depression only.

In the present study, several quality of life indicators were far worse among enrollees with comorbid PTSD and depression. Health-related unemployment emerged as the largest individual factor associated with PTSD and depression comorbidity, 


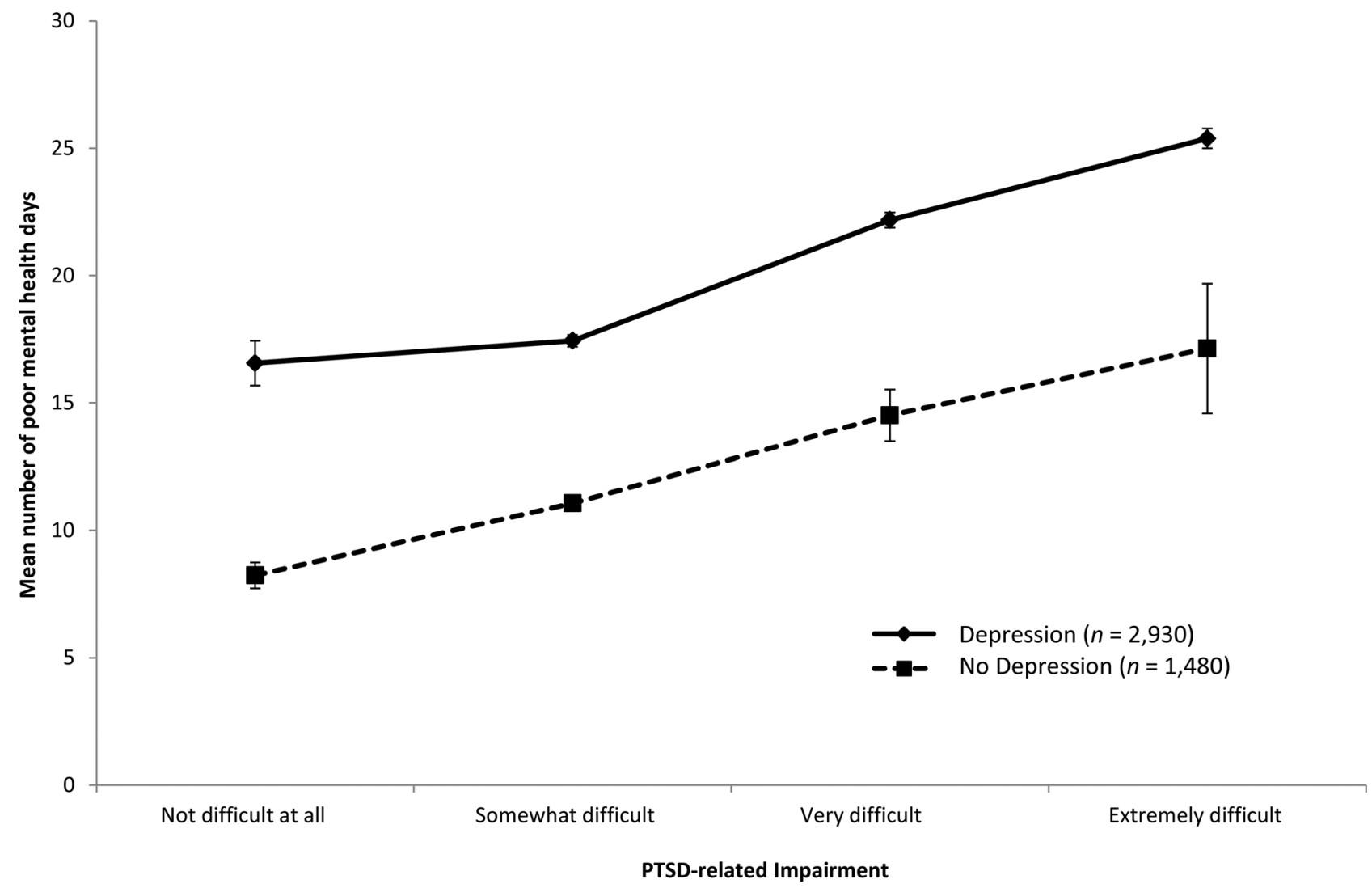

Figure 1. Mean number of poor mental health days in the prior 30 days among adult Registry enrollees with posttraumatic stress disorder (PTSD) and with or without depression by PTSD-related impairment at Wave 3. Error bars represent standard error.

suggesting that loss of social and economic resources and reduced access to health care leads to worsening PTSD and depression in a cyclical chain of events.

It is important to note that the psychopathologies examined are differentially associated with 9/11-related factors. Specifically, we observed a significant dose-response relationship between degree of 9/11 exposure and PTSD, but not depression. Chiu et al. (2011) reported similar results for 9/11-exposed firefighters. Our data suggest that there may be different mechanisms for the emergence of PTSD and depression as a result of exposure to trauma; major depression may emerge after PTSD, as dysthymia symptoms of PTSD are a prelude to depression.

Study strengths include the large sample size and use of validated instruments (PCL-17 and PHQ-8); although the latter do not yield clinical diagnoses of PTSD and depression, respectively, use of self-report measures is appropriate in large cohort studies where clinical assessment is not feasible. Additionally, the Registry contains a wide range of data on $9 / 11$ exposures and individual characteristics, including a history of traumatic life events experienced before and after 9/11 obtained at Wave 3. In contrast to other studies that examined comorbid PTSD and depression among distinct subgroups of affected individuals, enrollees represent a diverse group of persons with varying degrees of 9/11-related exposure and comprise individuals who lived or worked in close proximity to the WTC site, as well as rescue and recovery workers.

Several limitations must be considered. Loss to follow-up occurred between Registry survey waves, as $63 \%$ of the original adult cohort completed the Wave 3 survey. Persons who reported PTSD symptoms at Wave 1 were less likely to complete Wave 2 and 3 surveys; this nonresponse may be related to avoidance tendencies or behavioral dysfunction and suggests the possibility of underestimation (Brackbill et al., 2009). We do not know if individuals with depression were more or less likely to complete Wave 3, as the PHQ-8 was not administered at Waves 1 or 2. Furthermore, enrollees for whom there were missing items on the PCL-17 or PHQ-8 at Wave 3 were excluded from our analysis, which may have biased results. Moreover, we did not employ clinical diagnostic measures for PTSD and depression; we can only interpret self-report of PTSD and depression symptoms as probable. Selection bias is an additional limitation given that self-identified enrollees were more likely to report mental health symptoms and 9/11 exposures (Brackbill et al., 2009). Finally, data on 9/11 exposures were self-reported and were collected 2-3 years after $9 / 11$ and therefore may be subject to recall bias.

Adults who were directly and highly exposed to the events of 9/11 represent the population at greatest risk for debilitating, comorbid mental health outcomes. High prevalences of PTSD, 
depression, and comorbid PTSD and depression among adult Registry enrollees 10-11 years post-9/11 demonstrate the need for continued mental health symptom surveillance beyond a decade postdisaster. Additionally, these findings highlight the importance of ongoing screening and treatment for both PTSD and depression, as comorbid individuals have greater impairment, reduced quality of life, severe health symptoms and outcomes, and greater unmet mental health care need.

\section{References}

Adams, R. E., \& Boscarino, J. A. (2011). Perievent panic attack and depression after the World Trade Center disaster: A structural equation model analysis. International Journal of Emergency Mental Health, 13, 69-79.

Adams, R. E., Boscarino, J. A., \& Galea, S. (2006). Alcohol use, mental health status and psychological well-being 2 years after the World Trade Center attacks in New York City. American Journal of Drug and Alcohol Abuse, 32, 203-224. doi:10.1080/00952990500479522

American Psychiatric Association. (1994). Diagnostic and statistical manual of mental disorders ( $4^{\text {th }}$ ed.). Washington, DC: Author.

Blanchard, E. B., Jones-Alexander, J., Buckley, T. C., \& Forneris, C. A. (1996). Psychometric properties of the PTSD Checklist (PCL). Behaviour Research and Therapy, 34, 669-673.

Brackbill, R. M., Hadler, J. L., DiGrande, L., Ekenga, C. C., Farfel, M. R., Friedman, S., . . . Thorpe, L. E. (2009). Asthma and posttraumatic stress symptoms 5 to 6 years following exposure to the World Trade Center terrorist attack. Journal of the American Medical Association, 302, 502-516. doi:10.1001/jama.2009.1121

Brackbill, R. M., Stellman, S. D., Perlman, S. E., Walker, D. J., \& Farfel, M. R. (2013). Mental health of those directly exposed to the World Trade Center disaster: Unmet mental health care need, mental health treatment service use, and quality of life. Social Science and Medicine, 81, 110-114. doi:10.1016/j.socscimed.2012.12.016

Chiu, S., Niles, J. K., Webber, M. P., Zeig-Owens, R., Gustave, J., Lee, R., . . Prezant, D. J. (2011). Evaluating risk factors and possible mediation effects in posttraumatic depression and posttraumatic stress disorder comorbidity. Public Health Reports, 126, 201-209.
Gadermann, A. M., Alonso, J., Vilagut, G., Zaslavsky, A. M., \& Kessler, R. C. (2012). Comorbidity and disease burden in the National Comorbidity Survey Replication (NCS-R). Depression and Anxiety, 29, 797-806. doi:10.1002/da.21924

Galea, S., Ahern, J., Resnick, H., Kilpatrick, D., Bucuvalas, M., Gold, J., \& Vlahov, D. (2002). Psychological sequelae of the September 11 terrorist attacks in New York City. New England Journal of Medicine, 346, 982-987. doi:10.1056/NEJMsa013404

Hobfoll, S. E., Tracy, M., \& Galea, S. (2006). The impact of resource loss and traumatic growth on probable PTSD and depression following terrorist attacks. Journal of Traumatic Stress, 19, 867-878. doi:10.1002/jts.20166

Ikin, J. F., Creamer, M. C., Sim, M. R., \& McKenzie, D. P. (2010). Comorbidity of PTSD and depression in Korean War veterans: Prevalence, predictors, and impairment. Journal of Affective Disorders, 125, 279-286. doi:10.1016/j.jad.2009.12.005

Kroenke, K., Spitzer, R. L., \& Williams, J. B. (2001). The PHQ-9: Validity of a brief depression severity measure. Journal of General Internal Medicine, $16,606-613$

Murphy, J., Brackbill, R. M., Thalji, L., Dolan, M., Pulliam, P., \& Walker, D. J. (2007). Measuring and maximizing coverage in the World Trade Center Health Registry. Statistics in Medicine, 26, 1688-1701. doi: $10.1002 / \operatorname{sim} .2806$

Ruggiero, K. J., Del Ben, K., Scotti, J. R., \& Rabalais, A. E. (2003). Psychometric properties of the PTSD Checklist-Civilian Version. Journal of Traumatic Stress, 16, 495-502. doi:10.1023/A:1025714729117

SAS. (2008). Statistical Analysis System [Vers. 9.2]. Cary, NC: Author.

Stellman, J. M., Smith, R. P., Katz, C. L., Sharma, V., Charney, D. S., Herbert, R., . . . Southwick, S. (2008). Enduring mental health morbidity and social function impairment in world trade center rescue, recovery, and cleanup workers: The psychological dimension of an environmental health disaster. Environmental Health Perspectives, 116, 1248-1253. doi:10.1289/ehp.11164

Wisnivesky, J. P., Teitelbaum, S. L., Todd, A. C., Boffetta, P., Crane, M., Crowley, L., . . . Landrigan, P. J. (2011). Persistence of multiple illnesses in World Trade Center rescue and recovery workers: A cohort study. Lancet, 378, 888-897. doi:10.1016/S0140-6736(11)61180-X

Zahran, H. S., Kobau, R., Moriarty, D. G., Zack, M. M., Holt, J., \& Donehoo, R. (2005). Health-related quality of life surveillance-United States, $1993-$ 2002. MMWR Surveillance Summaries, 54, 1-35. 